\title{
Surface Modified Alumina Particles and Their Chemical Mechanical Polishing (CMP) Behavior on C-plane (0001) Sapphire Substrate
}

\author{
WANG Wei-Lei ${ }^{1,2,3}$, LIU Wei-Li ${ }^{1,3}$, BAI Lin-Sen ${ }^{3}$, SONG Zhi-Tang ${ }^{1,3}$, HUO Jun-Chao ${ }^{1,3}$ \\ (1. State Key Laboratory of Functional Materials for Informatics, Laboratory of Nanotechnology, Shanghai Institute of Microsystem \\ and Information Technology, Chinese Academy of Sciences, Shanghai 200050, China; 2. Graduate School of the Chinese Academy \\ of Sciences, Beijing 100049, China; 3. Xinanna Electronic Technology Co.,Ltd., Shanghai 201506, China)
}

\begin{abstract}
To improve the Chemical Mechanical Polishing (CMP) performance of alumina particles in aqueous solution, a suitable modification method was explored. Meanwhile, in order to improve their chemical mechanical performance, alumina particles were surface modified with N-(2-aminoethyl)-3-aminopropyltrimethoxysilane through silanization chemical reaction with their surface hydroxyl groups and complexation with $\mathrm{Al}$ and secondary amine. This work gives a detailed and thorough chemical reaction mechanism that $\mathrm{N}$-(2-aminoethyl)-3-aminopropyltrimethoxysilane grafted onto the surface of alumina. The compositions and structures of the modified alumina particles were characterized by Fourier transform infrared spectroscopy (FTIR), and X-ray photoelectron spectroscopy (XPS). The results supported that the $\mathrm{N}$-(2-aminoethyl)-3-aminopropyltrimethoxysilane was perfectly grafted onto the surface of alumina particles, which led to the modified alumina particles with better surface chemical and mechanical properties than unmodified alumina particles. Then, CMP performance of the unmodified and modified alumina particles on the sapphire substrate was tested. The results showed that the modified alumina particles exhibited higher material removal rate (MRR) and better surface quality than unmodified alumina particle. The focus is that the modified alumina particles manifested higher MRR at $\mathrm{pH} 10.00$ than the unmodified alumina particles at PH 13.00, which may open a way to reduce corrosion of equipment.
\end{abstract}

Key words: modification method; N-(2-aminoethyl)-3-aminopropyltrimethoxysilane; chemical mechanical polishing; Chemical Mechanical Polishing (CMP); alumina slurry

Smart phones, tablet computers and other mobile terminal have entered lato thousands of families. For example, smart phones, with the progress of society and the development of communications, are also developing rapidly. As an integral part of mobile phone, the phone screen is the large size, high definition and high scratch resistance. At present, compared to the glass material which is mainly applied in the mobile phone screen plate, sapphire material MOHS's hardness is up to nine, whose hardness and scratch resistance are three times as much as the IPHONE with corning gorilla glass. Its unique physical and optical properties make it a choice of mobile terminal window material optimization and upgrading. In addition, with the rapid development of light emitting diodes (LED), sapphire substrate material has been given more attention. Single crystal sapphire has vastly applied as a substrate in gallium nitride $(\mathrm{GaN})$ based LED which has good heat stability and chemical and mechanical properties ${ }^{[1-3]}$. The surface quality of sapphire has a vast important role in the performance of LED devices, so that the surface of sapphire is required to be smooth and have no defects. In order to reach this goal, chemical mechanical polishing (CMP) is the only accepted global planarization technology for sapphire.

Alumina, as an abrasive, has been used in sapphire substrate chemical mechanical polishing (CMP) for many years $^{[4-6]}$. The alumina powder used for polishing actually has a same material with sapphire, except that the difference between polycrystalline and single crystals. However, so far, $\alpha-\mathrm{Al}_{2} \mathrm{O}_{3}$ slurry is not used on a large scale on the polishing of sapphire. In the process of dispersion, $\mathrm{Al}_{2} \mathrm{O}_{3}$ particles are easily agglomerated, and these aggregates

Received date: 2017-01-17; Modified date: 2017-02-28

Foundation item: National Natural Science Foundation of China (51205387); Science and Technology Commission of Shanghai (11nm0500300); Science and Technology Commission of Shanghai (14XD1425300)

Biography: WANG Wei-Lei(1990-), male, candidate of Master degree. E-mail: awelly@mail.sim.ac.cn

Corresponding author: LIU Wei-Li, professor. E-mail: rabbitlwl@mail.sim.ac.cn 
hard and compact and it is difficult to effectively obtain dispersion in the polishing slurry. As a result, agglomeration of alumina particles in the polishing process can easily produce scratches. These shortcomings seriously hamper the alumina polishing slurry in the application of sapphire precision polishing. In this work, to improve the CMP performance of alumina particles in aqueous solution, a modification method, as a suitable method, was explored.

Alumina polishing slurry was divided into alkaline and acidic polishing liquid. Compared with the alkaline polishing slurry, acidic polishing slurry on equipment corrosion is more serious, so the markets are mainly composed of alkaline polishing slurry. Yet for alkaline alumina polishing slurry, alkalinity for alkaline polishing slurry has played a very important role, so the $\mathrm{pH}$ is 12.00 (from market research) above to boost material removal rate, which will seriously damage the equipment. So the preparation of a kind of low alkaline alumina polishing slurry has become a new topic. Surface modification ${ }^{[7-11]}$ became a preferred choice. Shen, et $a l^{[11]}$ employed $\Upsilon$-aminopropyltriethoxysilane (APS) to modify magnetite particles. Zhang, et $a l^{[12]}$ used $\Upsilon$-aminopropyltriethoxysilane to modify ceria particles and investigated its CMP performance. Tang, et $a l^{[7]}$ modified zinc oxide $(\mathrm{ZnO})$ particles with polymethacrylic acid (PMAA) in aqueous solution system. The dispersion stability of $\mathrm{ZnO}$ particles was crucially improved due to the introduction of grafted polymer on the surface of particles. Lei, et $a l^{[8-10]}$ modified alumina particles with silica or polymer obtaining a series of modified alumina particles and studied their CMP performance. As a silane coupling agent, N-(2-aminoethyl)-3-aminopropyltrimeth-oxysilane for double amino functional silane can change the material surface properties. In the present study, in order to reduce the alkaline of alumina slurry without lowering chemical mechanical polishing performance, we used N-(2-aminoethyl)-3-aminopropyltrimethoxysilane to modified alumina particles. We studied the reaction mechanism of the specific modification and established a model of rationalization modification reactions, and investigated its CMP performance on c-plane (0001) sapphire substrate.

\section{Experimental}

\subsection{Material}

$\mathrm{N}$-(2-aminoethyl)-3-aminopropyltrimethoxysilane and $\mathrm{KOH}$ was purchased from Sinopharm Chemical Reagent Co., Ltd.. Alumina particles powder with a Primary particle diameter of about $40 \mathrm{~nm}$ was purchased from Nanjing new materials Co., Ltd.. All the chemicals were AR.

\subsection{Preparation of the modified alumina particle}

In the work, the modified alumina particles were prepared in two steps. First, the N-(2-aminoethyl)-3-aminopropyltrimethoxysilane, ethanol and water were mixed in mass ratio of 5:18: 2 in a beaker, which were stirred for $30 \mathrm{~min}$ for hydrolysis at $50^{\circ} \mathrm{C}$. Second, the above solution were mixed with the pure alumina particles in a mass ratio of 2:5 together, which were stirred until the liquid will evaporate completely at $80^{\circ} \mathrm{C}$, using residual heat to completely evaporate the liquid. Then after several times of grinding, washing, centrifugation, we finally obtained the modified alumina particles by grinding.

\subsection{Polishing measurements}

The quality of the sapphire wafer before and after CMP were measured by the analytical balance (METTLER TOLEDO) to calculate the material removal rate according to Eq.(1):

$$
M R R=\frac{\Delta m}{T}
$$

Here, $\Delta m$ is quality variation in sapphire wafer before and after polishing, $T$ is the material removal time of sap-phire wafer. The content of alumina particles synthesized through an ALFOL method. The abrasive concentra-tion in the slurries was maintained $5 \mathrm{wt} \%$. The $\mathrm{pH}$ of the slurries were 10.00 and 13.00 adjusted by dilute $\mathrm{KOH}$ ( $2 \mathrm{~mol} / \mathrm{L}$ ). The polishing experiments were carried out using a CMP tester (BRUKER CP-4), with SUBA 600 stacked pad. To get repeatable results, the initial pad was cleaned for $30 \mathrm{~min}$ of breakout time. The polishing process parameters were set as follows: pad rotation speed, $100 \mathrm{r} / \mathrm{min}$; wafer rota-tion speed, $90 \mathrm{r} / \mathrm{min}$; down force, $6 \mathrm{psi}$; feed rate of the slurry, $125 \mathrm{~mL} / \mathrm{min}$; and polishing time, $30 \mathrm{~min}$; each time mass of slurry, $500 \mathrm{~g}$. Polishing rate in the work was an average of two polishing runs. All experi- ments were con-ducted at room temperature.

\subsection{Fourier transforms infrared spectroscopy experiences}

FTIR spectra were obtained on a Thermo Nicolet Nexus 470 FTIR spectrometer.

\subsection{X-ray photoelectron spectroscopy experiences}

Changes in the surface chemistry of the unmodified alumina and the modified alumina were studied by using an X-ray photoelectron spectroscope system (Axis Ultra, Kratos, Britain).

\section{Results and discussion}

\subsection{FTIR analysis of before and after the mod- ified alumina particles}

Fourier transform infrared spectroscopy was used to 
characterize structure of functional groups on the surface of the alumina. In Fig. 1, unmodified alumina surface had a very weak stretching vibration mode of hydroxyl groups at $3472 \mathrm{~cm}^{-1}$ and bending vibration mode of hydroxyl groups at $1338 \mathrm{~cm}^{-1}$. It showed that the presence of hydroxyl groups on the surface of the alumina before modification. By comparing the unmodified alumina, modified alumina had a series of absorption peak at $3371 \mathrm{~cm}^{-1}$ and $3294 \mathrm{~cm}^{-1}, 2927 \mathrm{~cm}^{-1}$ which belong to primary amine, secondary amine, reveal that alumina particles were modified successfully . After the alumina was modified, there was a special peak at $1116 \mathrm{~cm}^{-1}$ which belongs to alumino silicates that is $\mathrm{Al}-\mathrm{O}-\mathrm{Si}^{[11]}$. This explained the occurrence of a silanization reaction with hydroxyl groups.

\subsection{XPS analysis of before and after the modi- fied alumina particles}

Another method used for structure characterization was XPS. First of all, Fig. 2 showed that survey photoelectron spectra of alumina particles before and after modification. Both the unmodified alumina and modified alumina presents peaks of $\mathrm{Al}, \mathrm{C}$, and $\mathrm{O}$, while added peak of element $\mathrm{N}$ and $\mathrm{Si}$ appears for modified alumina. In addition, Table 1 showed binding energy of abrasives containing before and after modified alumina particles. By comparison, after modification of the surface of the alumina $\mathrm{Al}$ and $\mathrm{O}$ bonding energy could be reduced, which indirectly indicated that $\mathrm{N}$-(2-aminoethyl)-3-aminopropyltrimethoxysilane had been successfully modified alumina surface. Finally, Table 2 gave that the composition of elements on the surface of alumina particles before and after modification. By comparison with that only elements $\mathrm{Al}, \mathrm{O}$, and $\mathrm{C}$ existed on the surface of unmodified alumina, element $\mathrm{Si}$ and $\mathrm{N}$ were introduced on the surface of modified alumina. The introduction of $\mathrm{Si}$ and $\mathrm{N}$ elements, the increasing of the $\mathrm{C}$ elements, the reduction of $\mathrm{Al}$ and $\mathrm{O}$ elements only indicated $\mathrm{N}$-(2-aminoethyl)-3-aminopropyltrimethoxysilane had been

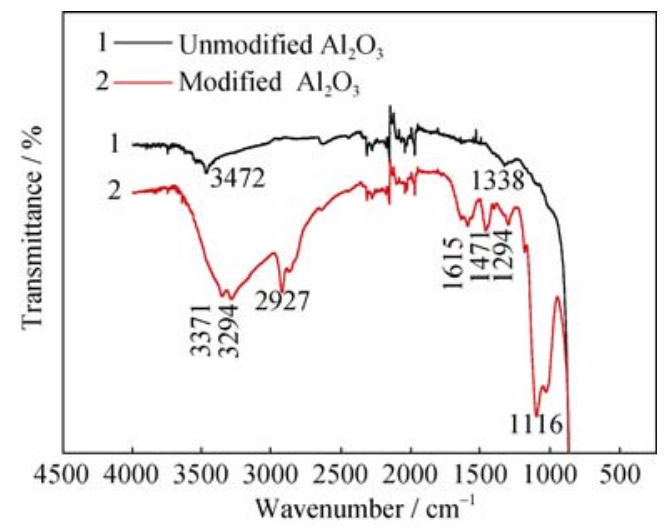

Fig. 1 FTIR spectra of alumina particles before and after modification

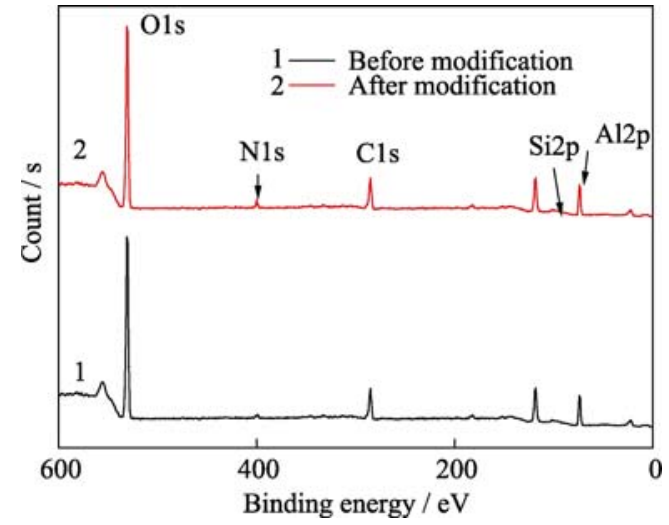

Fig. 2 XPS survey spectra of alumina particles before and after modification

Table 1 Binding energy of abrasives containing before and after modified alumina particles

\begin{tabular}{ccc}
\hline Elements in sample & $\mathrm{A} 12 \mathrm{p}$ & $\mathrm{O} 1 \mathrm{~s}$ \\
\hline \multirow{2}{*}{ Binding energy/eV } & 74.03 & 531.06 \\
& 73.08 & 530.87 \\
\hline
\end{tabular}

Table 2 Cmposition of elements on the surface of alumina particles before and after modification

\begin{tabular}{cccccc}
\hline Atomic\% $\%$ & $\mathrm{Al}$ & $\mathrm{O}$ & $\mathrm{C}$ & $\mathrm{N}$ & $\mathrm{Si}$ \\
\hline $\begin{array}{c}\text { Unmodified } \\
\text { alumina }\end{array}$ & 30.67 & 52.44 & 16.89 & 0 & 0 \\
$\begin{array}{c}\text { Modified } \\
\text { alumina }\end{array}$ & 27.35 & 46.41 & 21.19 & 2.77 & 2.28 \\
\hline
\end{tabular}

Table 3 Binding energy of Al2p

\begin{tabular}{cc}
\hline Chemical state & Band energy/eV \\
\hline$\left(-\mathrm{Si}\left(\mathrm{OCH}_{3}\right)_{2} \mathrm{O}-\right)_{x} \mathrm{Al}_{y}$ & 73.8 \\
$\mathrm{AlN}$ & 73.1 \\
\hline
\end{tabular}

Table 4 Binding energy of $01 \mathrm{~s}$

\begin{tabular}{cc}
\hline Chemical state & Band energy/eV \\
\hline$\left(-\mathrm{Si}\left(\mathrm{OCH}_{3}\right)_{2} \mathrm{O}-\right)_{x} \mathrm{Al}_{y}$ & 531.10 \\
$\mathrm{Al}_{2} \mathrm{O}_{3}$ & 530.30 \\
\hline
\end{tabular}

successfully modified alumina surface, but did not reveal $\mathrm{N}$-(2-aminoethyl)-3-aminopropyl-trimethoxysilane modified alumina surface.

To demonstrate the chemical reaction produced on the surface of alumina, modified alumina was analyzed by XPS. The spectra of the A12p, O1s, were showed in Fig. 3 and their BE were displayed in Table 3 and Table 4. In Fig. 3, the black line (a) and the red line (b) showed the real total intensity measured by XPS test, and the red line (a) and the blue line (b) showed the total intensity after curve fitting by using the XPSPEAK software. The closer between the real result and the fitting result means more precise measurement results.

The peak at the $\mathrm{BE}$ of $73.8 \mathrm{eV}$ (Fig. 3(a)) corresponds to $\mathrm{Al}(2 \mathrm{p})$ in $\left(-\mathrm{Si}\left(\mathrm{OCH}_{3}\right)_{2} \mathrm{O}-\right)_{x} \mathrm{Al}_{y}$ and the peak at the $\mathrm{BE}$ of 

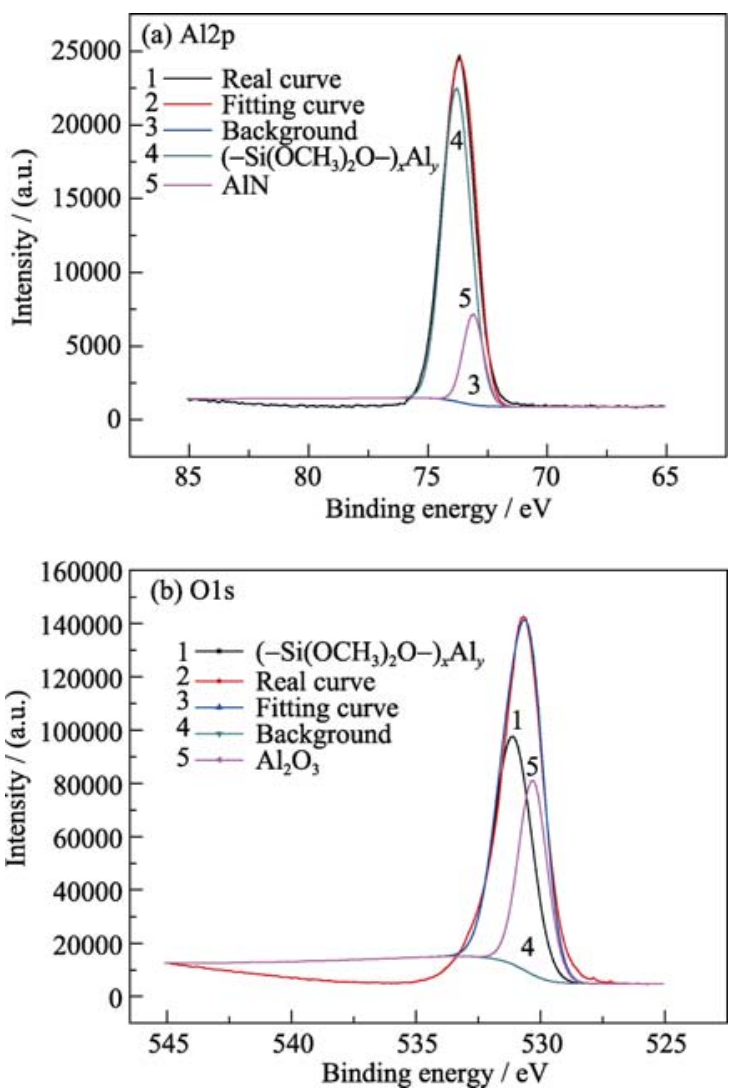

Fig. 3 XPS narrow scan spectra results of element A12p (a), O1s (b) in modified alumina

$531.10 \mathrm{eV}$ (Fig. 3(b)) corresponds to $\mathrm{O}(1 \mathrm{~s})$ in $(-\mathrm{Si}$ $\left.\left(\mathrm{OCH}_{3}\right)_{2} \mathrm{O}-\right)_{x} \mathrm{Al}_{y}$, which demonstrated that the first step reaction happened in the Fig. 4. The peak at the BE of $73.1 \mathrm{eV}$ (Fig. 3(a)) corresponds to $\mathrm{Al}(2 \mathrm{p})$ in $\mathrm{AlN}$ and the peak at the $\mathrm{BE}$ of $530.30 \mathrm{eV}$ (Fig. 3(b)) corresponds to $\mathrm{O}(1 \mathrm{~s})$ in $\mathrm{Al}_{2} \mathrm{O}_{3}$ which showed that alumina atoms happened the effect of aluminum ions. It is well known that aluminum ions are complexed with amines, but aluminum atoms cannot. The secondary amine with lone pair electrons was more likely to react with aluminum ions than primary amines of small electron donor groups and tertiary amines with large steric hindrance. Why is there a complex reaction between the aluminum atom and the secondary ammonia? As the first step of the reaction in Fig. 4 occurred, the alumina binding energy on the surface of the alumina was weakened so that the change in the state of the aluminum atom.

Although it could be seen in Fig. 3(a) that the area under the forestgreen line $\left(\left(-\mathrm{Si}\left(\mathrm{OCH}_{3}\right)_{2} \mathrm{O}-\right)_{x} \mathrm{Al}_{y}\right)$ was much larger than the fuchsia line (AIN), indicating that the first step was the primary role, the two-step reaction also played an important role and cannot be ignored. The above results illustrate that these two effects (Fig. 4) make N-(2-aminoethyl)3-aminopropyltrimethoxysilane solid alumina surface. Based on the above conclusions, Fig. 4 gave that the chemical reaction occurred in the process of modification.

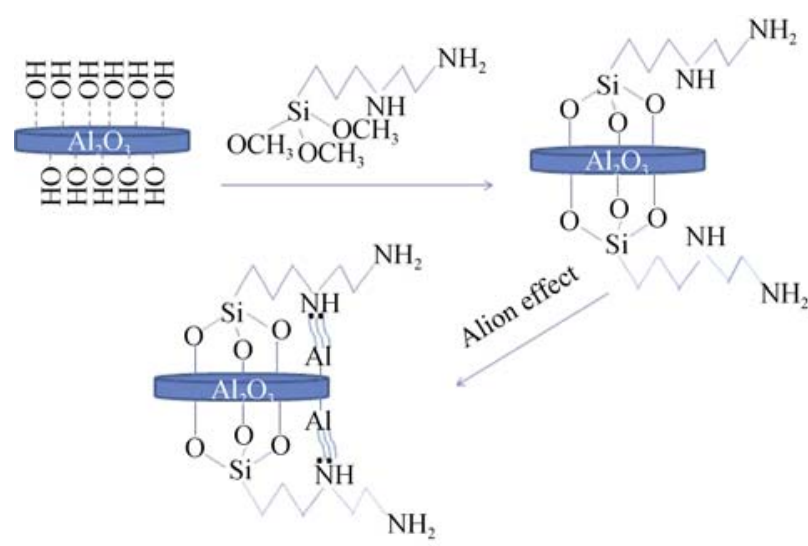

Fig. 4 Chemical reaction schemes for modification process

\subsection{CMP performances}

It is understood that abrasive loading has an important role on frictional interactions during $\mathrm{CMP}^{[13-14]}$. The friction force is wise to be seriously dependent on properties of the opposing surfaces, surface conditions, and the abrasive size, which all influence the contact area between the opposing surfaces ${ }^{[15]}$. A friction force is proportional to constant $\mathrm{COF}^{[16]}$. COF as a function of polishing time for sapphire substrates polished by unmodified alumina particles and modified alumina particles are showed in Fig. 5. In Fig. 5, it is observed that COF of sapphire CMP using modified alumina particles is higher than that of unmodified alumina particles.

In order to understand the difference in polishing performance between the unmodified alumina particles and the modified alumina particles at $\mathrm{pH} 10.00$ and 13.00, the MRR and RMS of sapphire substrate were shown in Table 5. It can be found that the MRR of alumina particles slurries at $\mathrm{pH} 13.00$ is two times larger than that of alumina particles slurries at $\mathrm{pH} 10.00$, which suggest that alkaline play a very important role. In addition, it cannot be only seen that the MRR of modified alumina particles is three times

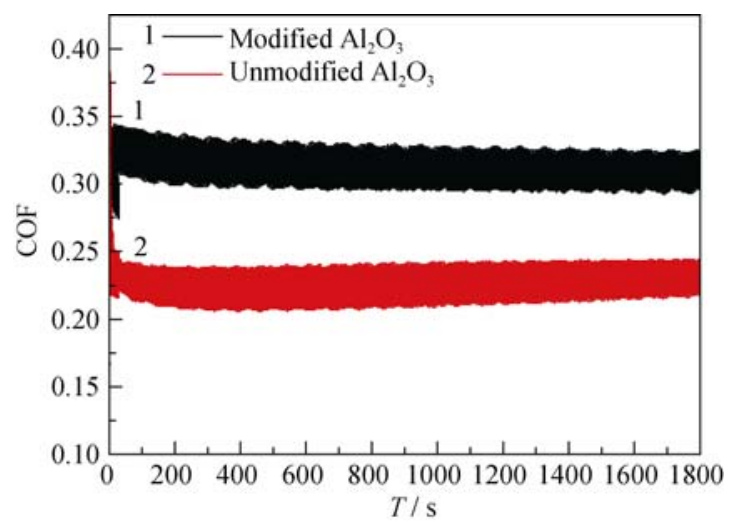

Fig. $5 \mathrm{COF}$ as a function of polishing time for sapphire substrates polished by unmodified alumina particles and modified alumina particles 
Table 5 Surface roughness $\left(R_{\mathrm{q}}\right)$ and material removal rate (MRR) by applying before and after modified alumina particles in different $\mathrm{pH}$

\begin{tabular}{ccccc}
\hline $\mathrm{pH}$ & Type of particles & $\begin{array}{c}\text { MRR } \\
(0.0001 \mathrm{~g} / 30 \mathrm{~min})\end{array}$ & $\begin{array}{c}\text { Before polishing } \\
R_{\mathrm{q}} \\
\text { Roughness } / \mathrm{nm}\end{array}$ & $\begin{array}{c}\text { After polishing } \\
R_{\mathrm{q}} \\
\text { Roughness } / \mathrm{nm}\end{array}$ \\
\hline 10.00 & Pure alumina & 46 & 0.968 & 0.610 \\
10.00 & Modified alumina & 127 & 0.610 & 0.329 \\
10.00 & Modified alumina & 139 & 0.981 & 0.315 \\
13.00 & Pure alumina & 93 & 0.916 & 0.552 \\
13.00 & Modified alumina & 122 & 0.552 & 0.311 \\
\hline
\end{tabular}

larger than that of pure alumina particles at $\mathrm{pH} 10.00$, but also surface quality is better. Above all, it can be displayed that the MRR of modified alumina particles at $\mathrm{pH} 10.00$ exceeded that of pure alumina particles at 13.00 , which insinuated that low alkaline slurry can achieve polishing effect of high alkaline slurry, in other words, this can greatly weak the chemical corrosion effect of polishing equipment. In order to further investigate the difference in polishing performance between unmodified alumina particles and modified alumina particles, the topographical micrographs of polished sapphire substrate surfaces were tested by AFM. As shown in Fig. 6, the surface before polishing rough and $R_{\mathrm{q}}$ is about 0.900 . After polishing with pure alumina particles, $R_{\mathrm{q}}$ decrease to about 0.500 .

However, after polishing with modified alumina particles, $R_{\mathrm{q}}$ decrease to about 0.300 . In other words, the modified alumina abrasive possesses higher surface planarization than pure alumina abrasive.

\section{Conclusions}

In this work, to improve the CMP performance of alumina particles in aqueous solution, a modification method, as a suitable method, was explored. Firstly, The alumina particles modified by $\mathrm{N}$-(2-aminoethyl)- 3-aminopropyltrimethoxysilane have a better CMP performance than unmodified alumina. Secondly, FTIR only indirectly proves that $\mathrm{N}$-(2-amino-ethyl)-3-aminopropyltrimethoxysilane have successful grafted on the surface of alumina particle, and XPS experiment directly proved this point. Innovatively, this paper gives a detailed chemical reaction mechanism that $\mathrm{N}$-(2-aminoethyl)-3-aminopropyltrimethoxy-silane grafted onto the surface of alumina, which $\mathrm{N}$-(2-aminoethyl)-3-aminopropyltrimethoxysilane through salanization reaction and complexation with $\mathrm{Al}$ and secondary amine firmly grafted onto the surface of alumina, in particular, complexation with $\mathrm{Al}$ and secondary amine is not negligiable. The consequence is that the modified

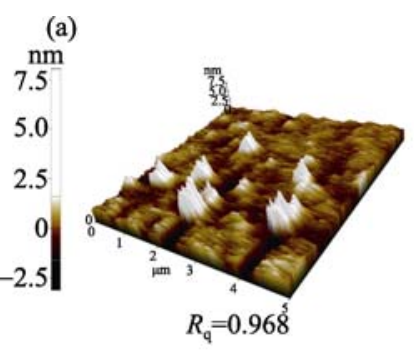

(c)

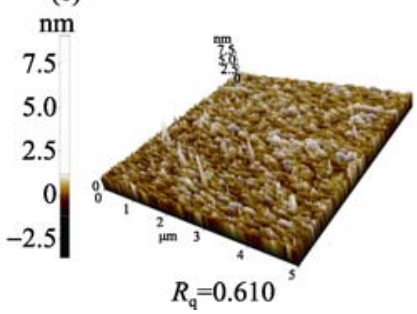

(b)

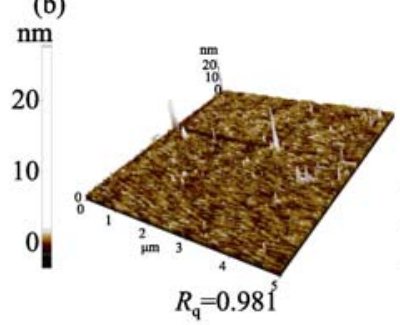

(d)

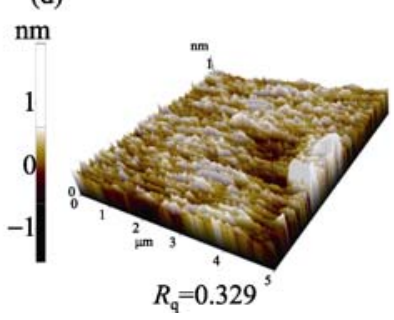

(e)

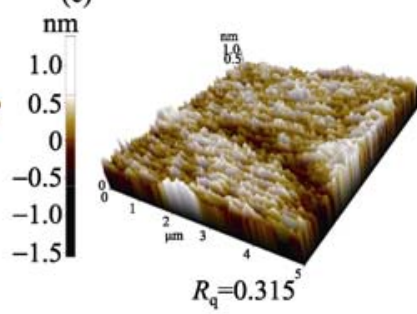

(g)

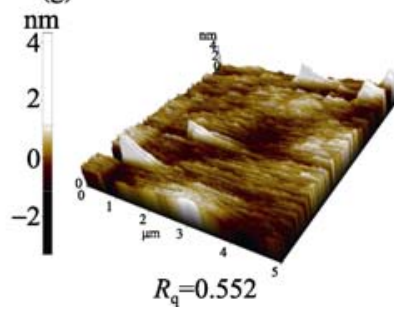

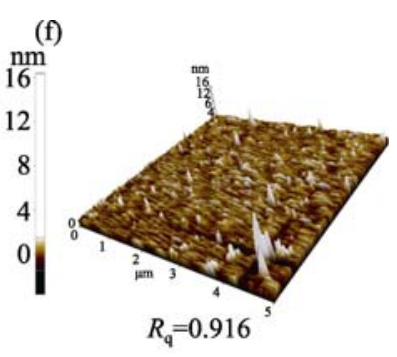

(h)

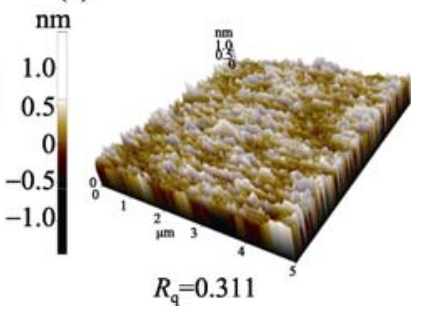

Fig. 6 (a, b, f) AFM morphologies of sapphire substrate before polishing; (c) polished by pure alumina particles at pH 10.00; (d) polished by modified alumina particle (using sapphire substrate polished by pure alumina particles (c)) at $\mathrm{pH} 10.00$; (e) polished by modified alumina particle at $\mathrm{pH}$ 10.00; (g) polished by modified alumina particle at $\mathrm{pH} 13.00$; (h) polished by pure alumina particles (using sapphire substrate polished by pure alumina particles $(\mathrm{g})$ ) at $\mathrm{pH} 13.00$ 
alumina friction coefficient is bigger that unmodified alumina, resulting the modified alumina particles exhibit higher material removal rate and better surface quality than unmodified alumina particle. Most important of all, the focus is that the modified alumina particles manifested higher MRR at $\mathrm{pH} 10.00$ than the unmodified alumina particles at $\mathrm{pH} 13.00$, which will provide ideas to reduce corrosion of equipment.

\section{References:}

[1] SAITO T, HIRAYAMA T, YAMAMOTO T, et al. Lattice strain and dislocations in polished surfaces on sapphire. J. Am. Ceram. Soc., 2005, 88: 2277-2285.

[2] NIU X H, LIU Y L, TAN B M, et al. Method of surface treatment on sapphire substrate. Transactions of Nonferrous Metals Society of China, 2006, 16: 732-734.

[3] TAKEUCHI T, TAKEUCHI H, SOTA S, et al. Optical properties of strained AlGaN and GaInN on GaN. Jpn. J. Appl. Phys., 1997, 36: L177-L179.

[4] LIMA R S, MARPLE B R. Thermal spray coatings engineered from nanostructured ceramic agglomerated powders for structural, thermal barrier and biomedical applications: a review. J. Therm. Spray Technol., 2007, 16: 40-63.

[5] KIM K T, KOO H Y, LEE G G, et al. Synthesis of alumina nanoparticle-embedded-bismuth telluride matrix thermoelectric composite powders. Mater. Lett. , 2012, 82: 141-144.

[6] ZOIS D, LEKATOU A, VARDAVOULIAS M, et al. Nanostructured alumina coatings manufactured by air plasma spraying: correlation of properties with the raw powder microstructure. J. Alloys
Compd., 2010, 495: 611-616.

[7] TANG E J, CHENG G X, MA X L, et al. Surface modification of zinc oxide nanoparticle by PMAA and its dispersion in aqueous system. Appl. Surf. Sci., 2006, 252: 5227-5232.

[8] LEI H, LU H S, LUO J B, et al. Preparation of $\alpha$-aluminag-polyacrylamide composite abrasive and chemical mechanical polishing behavior. Thin Solid Films, 2008, 516: 3005-3008.

[9] LEI H, ZHANG P Z. Preparation of alumina/silica core-shell abrasives and their CMP behavior. Appl. Surf. Sci., 2007, 253: 8754-8761.

[10] ZHANG Z F, LEI H. Preparation of $\alpha$-alumina/polymethacrylic acid composite abrasive and its CMP performance on glass substrate. Microelectron. Eng., 2008, 85: 714-720.

[11] SHEN X C, FANG X Z, ZHOU Y H, et al. Synthesis and characterization of 3-aminopropyltriethoxysilane-modified superparamagnetic magnetite nanoparticles. Chem. Lett., 2004, 33: $1468-1469$.

[12] ZHANG Z F, YU L, LIU W L, et al. Surface modification of ceria nanoparticles and their chemical mechanical polishing behavior on glass substrate. Appl. Surf. Sci., 2010, 256: 3856-3861.

[13] HOMMA Y. Dynamical mechanism of chemical mechanical polishing analyzed to correct Preston's empirical model. J. Electroanal. Chem., 2006, 153: G587-G590.

[14] MATSUDA T, TAKAHASHI H, TSURUGAYA M, et al. Characteristics of abrasive-free micelle slurry for copper CMP. J. Electrochem. Soc., 2003, 150: G532-G536.

[15] ABIADE J T, CHOI W, SINGH R K. Effect of $\mathrm{pH}$ on ceria-silica interactions during chemical mechanical. J. Mater. Res., 2005, 20: $1139-1145$.

[16] LIANG H, CRAVEN D R. Tribology in Chemical-Mechanical Planarization. Taylor \& Francis, Boca Raton, Fla., 2005.

\title{
氧化铝颗粒的表面改性及其在 C 平面 (0001) 蓝宝石 衬底上的化学机械抛光 (CMP) 性质
}

\author{
汪为䂞 ${ }^{1,2,3}$, 刘卫丽 ${ }^{1,3}$, 白林森 ${ }^{3}$, 宋志棠 ${ }^{1,3}$, 霍军朝 ${ }^{1,3}$
}

(1. 中国科学院 上海微系统与信息技术研究所, 信息材料国家重点实验室, 纳米技术实验室, 上海 200050; 2. 中国 科学院大学, 北京 100049 ; 上海新安纳电子科技有限公司, 上海 201506)

摘 要: 为了提高氧化铝颗粒的 CMP 性能, 本工作探索了一种合适的改性方法。同时, 为了改善其化学机械性能, 通 过与其表面羟基的硅烷化化学反应和与 $\mathrm{Al}$ 和仲胺的络合两种作用, 用 $\mathrm{N}$-(2-氨基乙基)-3-氨基丙基三甲氧基硅烷表面 改性氧化铝颗粒。本工作给出了化学反应机理, 即 N-(2-氨基乙基)-3-氨基丙基三甲氧基硅烷接枝到氧化铝表面。通过 傅里叶变换红外光谱(FTIR)和 X 射线光电子能谱(XPS)表征了改性氧化铝颗粒的组成和结构。结果表明: N-(2-氨基乙 基)-3-氨基丙基三甲氧基硅烷已被成功地接枝到氧化铝颗粒的表面, 导致改性比未改性的氧化铝颗粒具有更好的化学 和机械性能。测试了未改性和改性的氧化铝颗粒在蓝宝石基底上的 CMP 性能。结果显示: 改性氧化铝颗粒比未改性 氧化铝颗粒有更高的材料去除速率和更好的表面质量。即, 改性氧化铝颗粒在 $\mathrm{pH}=10$ 时比未改性氧化铝颗粒在 $\mathrm{pH}=13.00$ 时表现出更高的材料去除率, 这将为减少设备腐蚀提供新思路。

关 键 词: 改性方法; N-(2-氨基乙基)-3-氨基丙基三甲氧基硅烷; 化学机械抛光; CMP; 氧化铝抛光液 中图分类号: TQ174

文献标识码：A 